\title{
Hypertension and angiotensin system inhibitors in patients with metastatic renal cell carcinoma
}

\author{
Lisa Derosa, ${ }^{1}$ Hassane Izzedine, ${ }^{2}$ Laurence Albiges, ${ }^{1}$ Bernard Escudier ${ }^{1}$ \\ ${ }^{1}$ Gustave Roussy Cancer Center, University of Paris-Saclay, Villejuif; ${ }^{2}$ Department of Nephrology \\ and Pathology, Pitié Salpêtrière Hospital, Paris, France
}

\begin{abstract}
Arterial hypertension (HTN) is a class effect of anti-vascular endothelial growth factor (VEGF) therapies, including the monoclonal antibody bevacizumab. Data are conflicting regarding the role of the renin-angiotensin system on angiogenesis and recent data suggest that the use of angiotensin system inhibitors (ASIs; angiotensin receptor blockers or angiotensin-converting enzyme inhibitors) is associated with improved survival in metastatic renal cell carcinoma (mRCC), particularly when used with VEGF targeted therapies. The aim of this review is to discuss the available treatment options for $\mathrm{mRCC}$ and associated incidence of hypertension as well as summarize the known data about ASIs use and mRCC. Additionally, given that the optimal management of HTN remains unclear, we will focus on prevention strategies and propose potential therapeutic approaches.
\end{abstract}

\section{Introduction}

Hypertension (HTN) is one of the most commonly found comorbidity in cancer patients and at the same time being known as an established risk factor for renal disease and renal cell carcinoma (RCC)., Patients with metastatic RCC (mRCC), compared with those with non-

Correspondence: Lisa Derosa, Gustave Roussy Cancer Center, University of Paris-Saclay, 114 rue Edouard Vaillant, Villejuif F-94805, France.

Tel.: +33.1.42113326 - Fax: +33.1.42115305.

E-mail:deros.lisa@gmail.com

Key words: Hypertension; angiotensin system inhibitors; renal cell carcinoma; renin-angiotensin system.

Contributions: the authors contributed equally.

Conflict of interest: the authors declare no potential conflict of interest.

Received for publication: 19 August 2016.

Revision received: 6 October 2016.

Accepted for publication: 2 November 2116.

This work is licensed under a Creative Commons Attribution NonCommercial 4.0 License (CC BY-NC 4.0).

(C) Copyright L. Derosa et al., 2016

Licensee PAGEPress, Italy

Oncology Reviews 2016; 10:298

doi:10.4081/oncol.2016.298
RCC malignancies, have a significantly higher incidence of HTN.$^{3,4}$ In fact, HTN can be regarded as one of the most frequently observed class-, as well as dose-dependent adverse events of vascular endothelial growth factor/receptor (VEGF/VEGFr) inhibitors, also representing the best-documented one. ${ }^{5}$ The risk and the severity of HTN related to VEGF inhibitors (VEGFi) depend on the type of drug, dose and schedule used, age of patients and the presence of cardiac disease. Considering the same drug, it is also higher in patients with mRCC compared with other cancers as reported with sorafenib, ${ }^{6}$ sunitinib $^{7}$ and axitinib ${ }^{8}$ phase III trials but surprisingly not in those with pazopanib. ${ }^{9}$ As a known class-specific side effect for anti-VEGF agents, HTN has been reported as predictive of better outcome and as a potential biomarker, especially with axitinib, to guide dose adjustments for individual patients. ${ }^{10}$ Even though pre-existing HTN has been reported as a prognostic factor in mRCC treated with VEGFi. ${ }^{11,12}$, its recognition is an important issue because poorly controlled HTN could lead to serious vascular events. For example, a higher incidence of intracerebral hemorrhage has been reported in patients with mRCC treated with tyrosine kinase inhibitors (TKI), probably related to uncontrolled HTN at diagnosis. ${ }^{13}$ Optimal anti-hypertension medication has not yet been defined. This paper will discuss HTN and its management strategies, as reported in pivotal studies, and in the literature, with a focus on angiotensin system inhibitors (ASI).

\section{Prevalence of hypertension caused by angiogenic inhibitor agents in renal cell carcinoma trials}

Although HTN is a very frequent adverse effect among cancer patients treated with VEGFi, the exact prevalence and the risk of HTN in RCC patients who receive these drugs have not yet been specified. The reported incidence of all-grade HTN ranges from 25\% with sorafenib and sunitinib to $42 \%$ with pazopanib and axitinib. ${ }^{6-8,14}$ Table $1^{6-8,14-20}$ summarizes the findings of available options in phase III studies in RCC concerning HTN. Bevacizumab represents a monoclonal antibody targeting the VEGF pathway. ${ }^{21}$ The approval of bevacizumab in RCC patients was based on the results from the AVOREN trial ${ }^{17}$ and the CALGB 90206 trial. $^{18}$ The toxicities of anti-VEGF therapy observed in these studies included proteinuria, bleeding and HTN, as previously observed in other malignancies. Specifically, in the AVOREN and in the CALGB 90206 trials the incidence of HTN was $26 \%$ and $28 \%$ in the bevacizumab plus interferon arm, whereas the grade 3 or 4 incidence of HTN was noted as $6 \%$ and $11 \%$, respectively. ${ }^{19}$ In a meta-analysis, referring to over 12,000 patients treated for different solid tumors in phase II or III clinical trials, ${ }^{22}$ the overall incidence of all blood pressure (BP) elevation events was $24 \%$ [ $95 \%$ confidence interval (CI), 20 - 
29\%] among patients receiving bevacizumab and the incidence of grade 3 or 4 HTN was found in $8 \%$ of patients (95\% CI, 6-10\%). ${ }^{22}$ Moreover, a previously published meta-analysis of over 1800 patients, reported bevacizumab administration being correlated with a significant dose-dependent increase in the risk of HTN. ${ }^{23}$ Interestingly, in this study two groups of patients (with RCC and breast cancer), showed the highest relative risk of HTN development; it may indicate that HTN incidence may be associated with cancer type. Sorafenib is a multi-targeted TKI, which affects Raf-kinase, VEGFR-1, -2 and -3 , plateletderived growth factor receptor (PDGFR)- $\beta$, FMS like tyrosine kinase 3 (FLT-3), c-KIT and RET receptor tyrosine kinase. ${ }^{24}$ In RCC patients previously treated with cytokines, sorafenib was compared with placebo in the TARGET trial. In this case, sorafenib exhibited a higher incidence of all grade HTN (17\%), but only $4 \%$ of grade 3 or 4 HTN. ${ }^{6}$ Furthermore, in a meta-analysis of over 4500 patients (with different cancers) participating in clinical trials of sorafenib, an overall incidence of HTN (all grades) of $23.4 \%$ ( $95 \% \mathrm{CI}, 16.0-32.9 \%$ ) was shown while the incidence of grade 3 or 4 HTN was $5.7 \%$ (95\% CI, 2.5-12.6\%). Sorafenib was positively correlated with the increased risk of HTN (all grades) manifestation [relative risk $(\mathrm{RR})=6.11,95 \% \mathrm{CI}, 2.44-15.32 ; \mathrm{P}<0.001] .{ }^{25}$ Indeed, the largest meta-analysis in several solid cancer patients treated with sorafenib, involved 13,555 patients treated in a total of 14 randomized controlled trials and 39 prospective single-arm trials and it showed that the relative risk of all-grade and high-grade HTN associated with sorafenib was 3.07 (95\% CI, 2.05-4.60; $\mathrm{P}<0.01)$ and 3.31 (95\% CI, 2.21$4.95 ; \mathrm{P}<0.01)$, respectively. The overall incidence of sorafenib-induced all-grade and high-grade HTN was 19.1\% (95\% CI, 15.8-22.4\%) and $4.3 \%$ (95\% CI, 3.0-5.5\%), respectively. Finally, a significantly higher incidence of HTN was also noted in patients with RCC compared with those with non-RCC malignancies (all-grade: 24.9\% (95\% CI, 19.730.1\%) vs 15.7\% (95\% CI, 12.1-19.3\%); $\mathrm{P}<0.05$; high-grade: 8.6\% (95\% CI, $6.0-11.2 \%$ ) vs $1.8 \%$ (95\% CI, 0.9-2.6\%); $\mathrm{P}<0.05) .^{3}$

Sunitinib is a multi-target TKI with inhibitory effects on multiple tyrosine kinase receptors, including VEGFR-1, -2 and -3, PDGFR- $\alpha$ and $-\beta$, FLT-3, c-KIT, and RET receptor tyrosine kinase.$^{26}$ In RCC patients, sunitinib compared to Interferon, provided a significant improvement in progression-free survival (PFS) (11 vs 5 months) in treatment naïve patients at the expense of $24 \%$ of all grade HTN and $8 \%$ of high grade
HTN. ${ }^{7}$ A meta-analysis by Zhu et al. of nearly 5000 patients on sunitinib for the treatment of RCC and gastrointestinal stromal tumors, showed that all grade incidence of HTN was $21.6 \%(95 \% \mathrm{CI}=18.7$ $24.8 \%)$ while the incidence of grade 3 or $4 \mathrm{HTN}$ was $6.8 \%(95 \% \mathrm{CI}=5.3$ $8.8 \%) .{ }^{27}$ Sunitinib was also correlated with a significant increase in the relative risk of grade 3 or $4 \mathrm{HTN}$ ( $\mathrm{RR}=22.72,95 \% \mathrm{CI}=4.48-115.29$; $\mathrm{P}<0.001$ ) and similarly with the above studies for bevacizumab, there was a statistically significant difference between the incidence of allgrade and high-grade HTN in RCC patients and non-RCC patients (RR 1.32, 95\% CI, 1.18-1.48\%; P<0.001 and RR 1.57, 95\% CI, 1.22-2.02\%; $\mathrm{P}=0.001$, respectively).

Similarly, Pazopanib is a multi-target TKI, targeting VEGFR-1, -2 and -3 , PDGFR- $\alpha$ and $-\beta$, and $c$-KIT. ${ }^{28,29}$ The therapeutic efficacy of pazopanib in patients with mRCC has been demonstrated in three phase III randomized controlled trials: the VEG105192 ${ }^{14}$ and COMPARZ trials, ${ }^{15}$ and a crossover trial (PISCES) ${ }^{16}$ investigating patient preference. In the VEG105192 double-blind efficacy trial, treatment-naïve or cytokine-pretreated patients received either pazopanib $800 \mathrm{mg}$ once daily or placebo. The study reported a $40 \%$ of incidence in all grade HTN and $13 \%$ of incidence in high-grade HTN with pazopanib. The openlabel, non-inferiority COMPARZ trial compared the efficacy and safety of pazopanib and sunitinib as first-line therapy in 1110 patients with clear-cell mRCC. The phase IIIb PISCES trial was a double blind, crossover study evaluating patient preference for sunitinib or pazopanib. Patients with mRCC were randomly assigned to pazopanib $800 \mathrm{mg} /$ day for 10 weeks, then a 2 -week washout followed by sunitinib $50 \mathrm{mg}$ /day for 10 weeks (4 weeks on, 2 weeks off, 4 weeks on), or the reverse sequence. In both studies, regarding the two groups of patients, no statistically significant differences in grade 3 and 4 HTN or in the overall grade HTN was observed (Table 1). ${ }^{6-8,14-20}$ Indeed, a meta-analysis of over 1600 patients showed that the risk of HTN (all grades) in patients who follow pazopanib therapy ( $R R=4.97,95 \% \mathrm{CI}, 3.38-7.30$; $\mathrm{P}<0.001)$ was even higher than in patients treated with sunitinib $(\mathrm{RR}=2.20,95 \% \mathrm{CI}, 1.92-2.52 ; \mathrm{P}<0.001)$ or sorafenib $(\mathrm{RR}=1.99,95 \% \mathrm{CI}$, 0.96-1.53; $\mathrm{P}<0.001)$. In addition, the overall incidence of pazopanibassociated HTN (all grades) was 35.9\% (95\% CI, 31.5-40.6\%) and HTN (grade 3 or 4 ) was $6.5 \%(95 \% \mathrm{CI}, 5.2-8.0 \%)$. In contrast with a similar observation of sunitinib therapy, a statistically significant difference

Table 1. Hypertension related to available options in phase III studies in renal cell carcinoma.

\begin{tabular}{|c|c|c|c|c|c|}
\hline Agent & Reference & Regimen & Patient, n & & n $(\%)$ \\
\hline & & & & All grade & Grade $3 / 4$ \\
\hline Sorafenib & Escudier et al. ${ }^{6}$ & Placebo & 452 & 2 & $<1$ \\
\hline & & Sorafenib, $400 \mathrm{mg}$ twice day & 451 & 17 & 4 \\
\hline Sunitinib & Motzer et al. ${ }^{7}$ & IFN & 360 & 1 & 1 \\
\hline & & Sunitinib, $50 \mathrm{mg} /$ day & 375 & 24 & 8 \\
\hline Pazopanib & Sternberg et al..$^{14}$ & Placebo & 145 & 10 & $<1$ \\
\hline & & Pazopanib & 290 & 40 & 13 \\
\hline Pazopanib & Motzer et al. ${ }^{15}$ & Sunitinib & 553 & 41 & $15 /<1$ \\
\hline & & Pazopanib & 557 & 46 & $15 /<1$ \\
\hline Pazopanib & Escudier et al. ${ }^{16}$ & Sunitinib & 148 & 26 & $9 / 0$ \\
\hline & & Pazopanib & 153 & 23 & $8 / 0$ \\
\hline Bevacizumab & Escudier et al. ${ }^{17}$ & Placebo + IFN & 322 & 9 & $<1$ \\
\hline & & IFN + bevacizumab $10 \mathrm{mg} / \mathrm{kg}$ & 327 & 26 & 3 \\
\hline Bevacizumab & Rini et $a l .{ }^{18,19}$ & Placebo + IFN & 349 & 28 & 0 \\
\hline & & IFN + bevacizumab $10 \mathrm{mg} / \mathrm{kg}$ & 366 & 4 & 11 \\
\hline Axitinib & Rini et al..$^{8}$ & Sorafenib & 355 & 29 & $10.7 /<1$ \\
\hline & & Axitinib & 359 & 40.4 & $15.3 /<1$ \\
\hline Cabozantinib & Motzer et al. ${ }^{20}$ & Everolimus & 332 & 7 & 3 \\
\hline & & Cabozantinib & 331 & 37 & 1 \\
\hline
\end{tabular}

IFN, interferon. 
between the incidence of pazopanib-induced HTN in RCC and non-RCC patients could not be demonstrated. Axitinib is a selective TKI inhibitor of VEGFR-1, -2 and $-3 .{ }^{30}$ In patients with mRCC on axitinib, HTN had an incidence of $42 \%$ (17\% had a grade 3$)$ in the phase III AXIS trial. ${ }^{31}$ In a meta-analysis including 10 clinical trials, HTN rate in 1908 axitinibtreated patients, was $40.1 \%(95 \% \mathrm{CI}, 30.9,50.2 \%)$ and $13.1 \%(95 \% \mathrm{CI}$, $6.7,24.0 \%$ ) for all grade and grade 3 or 4 , respectively. Considering only the RCC patients, the use of axitinib was associated with an increased risk of developing all grade and high grade hypertension compared to non-RCC patients and the overall incidence of high grade HTN with axitinib was higher than with the other VEGFR-TKI. ${ }^{4}$ The incidence rate of treatment-induced HTN associated with axitinib seems to be higher than those described for all multi-targeted inhibitor. Finally, cabozantinib, a targeted agent against MET and VEGFR-2, has shown promising results and could become another second line option for patients with RCC. Also for cabozantinib in patient with RCC, the most common grade 3 or 4 adverse event was HTN (15\%) in the pivotal trial METEOR. while the overall incidence of HTN (all grade) was $37 \% .^{20}$ In patient with metastatic thyroid cancer, treated with cabozantinib in the phase III trial, the overall incidence of HTN and grade 3-4 of HTN were lower than those observed for RCC (32.7 \% and 8.4\%, respectively). ${ }^{32}$

\section{Pathogenesis of hypertension}

Although the exact mechanism by which VEGF pathway inhibitors lead to a rise in BP is not fully understood, key hypotheses have been generated. Inhibition of endothelial nitric oxide (NO) synthase, increased vascular stiffness, activation of the endothelin-1 system and inhibition of the renin-angiotensin system have been implicated. ${ }^{11,33}$ The HTN induced by antiangiogenic drugs is probably related to an increase in systemic vascular resistance (SVR). Mechanisms inducing high SVR include neurohormonal factors (such as renin, and aldosterone, catecholamines, epinephrine, norepinephrine, endothelin I), vascular rarefaction (decrease in the density of microvessels), and endothelial dysfunction associated with a decrease in NO production and an increase in oxidative stress. An important part of the mechanism of HTN associated with VEGF inhibition is thought to involve decreased production of NO in the wall of arterioles and other resistance vessels. VEGF increases NO synthesis through upregulation of endothelial NO synthase, and VEGF inhibition diminishes NO synthesis. $^{34,35}$ Indeed, the inhibition of VEGF may cause increased SVR ${ }^{36,37}$ and vascular rarefaction ${ }^{38}$ leading to HTN. Furthermore, VEGF inhibition may induce renal thrombotic microangiopathy leading to HTN ${ }^{39}$

\section{Angiotensin system inhibitors in renal cell car- cinoma}

There has been experimental evidence that angiotensin II is involved in promoting cancer development. Angiotensin II is a powerful mitogen and facilitates cellular growth and proliferation through transforming growth factor- $\beta^{40}$ epidermal growth factor and tyrosine kinase. Angiotensin II also regulates apoptotic mechanisms and angiogenesis by up-regulating VEGF expression ${ }^{41}$ stimulating neovascularization $^{42}$ and DNA synthesis ${ }^{43}$ which is a requirement for tumor growth. ${ }^{44}$ ASI including angiotensin-converting enzyme inhibitors (ACEIs) and angiotensin receptor blockers (ARBs), are commonly used as anti-hypertensive and anti-proteinuric agents. There is significant evidence that ASI may have induced cytostatic effects on the cultures of several lines of neoplastic cells and also delayed the growth of differ- ent types of tumors in a variety of experimental animals. ${ }^{45-48}$ These drugs were found to suppress the signal transduction mediated by growth factors through AT1R antagonism ${ }^{49}$ and to inhibit the proliferation of cancer cells through activation of the peroxisome proliferatoractivated receptor- $\gamma .{ }^{50}$ Additionally, studies of human clear-cell RCC have demonstrated that angiotensin II receptor expression strongly correlates with tumor aggressiveness and decreased survival. ${ }^{51}$ Since that time, several retrospective studies have investigated the association between ASIs and cancer progression and survival. A meta-analysis comparing the use and nonuse of ACEIs or ARBs in several cancer patients (4964 patients treated in a total of 11 trials) showed that the use of ACEIs or ARBs resulted in a significant improvement in disease free survival [hazard ratio (HR) $0.60 ; 95 \% \mathrm{CI}, 0.41-0.87 ; \mathrm{P}=0.007$ ] and overall survival (OS) (HR 0.75; 95\% CI 0.57-0.99; $\mathrm{P}=0.04$ ). Analysis according to cancer type showed benefits in urinary tract cancer (HR 0.22 ), colorectal cancer (HR 0.22), pancreatic cancer (HR 0.58), and prostate cancer (HR 0.14), but not in breast cancer and hepatocellular cancer. This meta-analysis provides evidence that the use of ACEIs or ARBs in cancer patients can lead to a 40 and $25 \%$ reduction in the risk of cancer recurrence and mortality ${ }^{52}$ Furthermore, there seems to be a synergistic interaction between ASIs and VEGF-targeted therapy given that these agents are thought, at least in part, to augment a similar pathway. In a murine xenograft model of RCC, the combination of sunitinib and telmisartan, compared to sunitinib alone, revealed an enhancement of the blockage of the VEGF pathway on renal tumor resulting in a decrease in neoangiogenesis and an increase in necrosis. ${ }^{53}$ Recent clinical evidences suggest that use of ASI and ARB may be associated with improved outcomes in kidney cancer patients particularly when they are used with VEGF therapies. Three prior studies have reported on a significant association of ASI use (at baseline or within first 30 days of VEGF-targeted therapy) and survival for patients with mRCC using a VEGF-targeted therapy. The first compared ASI users $v s$ non-users in a cohort of 127 patients with mRCC treated with sunitinib and found a significant association with PFS (HR 0.54, P=0.0055, medians of 13 versus 6 months) and a non-statistically significant improvement in OS (HR 0.67, $\mathrm{P}=0.21$, medians of 30 versus 23 months). ${ }^{54}$ Secondly, in a cohort of 213 patients with mRCC treated with sunitinib, ASI users were reported to have a significantly improved OS (HR 0.40) and PFS (HR 0.55). ${ }^{11}$ Finally, a larger study of mRCC patients treated with a range of VEGF-targeted therapies (sunitinib, sorafenib, axitinib, bevacizumab, temsirolimus and interferon- $\alpha$; 4736 patients included) found that ASI users have improved OS (HR 0.84, $\mathrm{P}=0.0105,26.68$ versus 18.7 months) compared to users of other anti-hypertensive agents, and that this association was not as prominent for patients treated with non VEGF-targeted agents. ${ }^{12}$ The authors hypothesized that this may be related to the ability of ASIs to synergize with antiangiogenics to inhibit tumor cell proliferation and angiogenesis. Huillard et al. suggested that the action of ASI on muscle mass may result in less sarcopenia, a well-documented cause of overexposure and excessive toxicity to TKIs. Hence, the therapeutic index of VEGF-targeted therapies may be improved by ASI, resulting in subsequent longer duration of treatments, higher dose-intensity, and finally improved efficacy. ${ }^{55}$ But in these analyses, there was no mention whether the patients under ASI had less early dose-limiting toxicities or less treatment interruptions. In contrast, a study of 1120 patients using a range of VEGF targeted therapies (sunitinib, sorafenib, pazopanib) across a number of indications (including mRCC) found no significant association (HR 0.92) between ASI use and 0S. ${ }^{56}$ Recently, Sorich et al. reported a secondary pooled analysis of two phase III randomized controlled trials (RCTs) of patients with mRCC: NCT00334282 comparing pazopanib to placebo and NCT00720941 comparing pazopanib to sunitinib. ${ }^{57}$ Unlike the other studies, ASI users were defined as patients using an ASI only at baseline. Of 1545 patients pooled from the two RCTs, 649 (42\%) were using one or more antihypertensive drugs at baseline, 385 (59\%) of 
which were using an ASI. In the multivariable analysis of patients using pazopanib or sunitinib, no significant association was observed between baseline ASI use and OS (HR 0.97, $\mathrm{P}=0.80$ ) or PFS (HR 0.88, $\mathrm{P}=0.17$ ). Exploratory subgroup analysis of NCT00720941 highlighted that the effect of baseline ASI use on OS may differ between patients treated with sunitinib and pazopanib. Post hoc subgroup analysis of the COMPARZ clinical trial highlighted that the relative efficacy of pazopanib and sunitinib may differ depending on background use of ASIs with results suggesting a greater benefit among sunitinib-treated patient using ASIs compared to pazopanib-treated patients.

\section{Management of hypertension}

The management of HTN has been individualized in terms of the HTN stage and other special situations (i.e., coronary disease or heart failure) that may coexist with HTN. ${ }^{58}$ However, all published guidelines for HTN management give no clear recommendations about cancer patients who suffer from HTN caused by antiangiogenic drugs. At the onset, HTN should be treated immediately, with standard hypertensive therapy based on the current guidelines of the European Society of HTN. ${ }^{59}$ Specific guidelines consist of actively monitoring $\mathrm{BP}^{60}$ throughout treatment with VEGF inhibitors, with more frequent assessments during the first cycle of treatment; this is because preexisting HTN should be identified and addressed before initiation of therapy ${ }^{61}$ to avoid serious vascular events. The optimal BP level should be less than $140 / 90 \mathrm{mmHg}$ for most patients, but it should be set up on a case-bycase basis. ${ }^{62}$ The JCN7 guidelines proposed a lower level of BP $(<130 / 90 \mathrm{mmHg})$ in high-risk patients, i.e., those with diabetes, chronic kidney disease and coronary artery disease. In addition, regarding cancer patients who receive VEGFi agents, it has been suggested that antihypertensive treatment accompanied with dose modification of VEGFi or even a second antihypertensive regimen should be initiated when the BP reaches above 140/90 $\mathrm{mmHg}$ level or a $20 \mathrm{mmHg}$ increase in diastolic BP above baseline. ${ }^{63}$ Especially if the VEGFi-induced HTN is severe or persistent even after the administration of antihypertensive drugs or the individualized dose adaptation of VEGFi, temporarily or permanently stopping of antiangiogenic treatment may be required. Nevertheless, it has been observed that most cancer patients with VEGFi-induced HTN respond sufficiently to the standard schemes of antihypertensive treatment. ${ }^{64}$ Antihypertensive therapies including ASI (ACE and ARB), or adrenoreceptor blockers, calcium channel blockers (CCBs) as well as diuretics have been used as treatment of VEGFiinduced HTN. Optimal anti-hypertension medication has not yet been defined, and clinicians should consider individual patients' comorbid conditions when selecting classes of antihypertensive drugs for treatment. It is generally admitted that ACE and ARB are more effective in treating anti-VEGF-associated HTN, are better tolerated and have antiproteinuric effects, which may contribute to protection of renal function. ${ }^{65,66}$ CCBs may reduce microvascular rarefaction and improve angiogenesis but concerns have been raised over the safety of CCBs, particularly non-dihydropyridines, because they interfere with CYP3A4 activity. ${ }^{25,67,68}$ Due to the fact that VEGFi agents are metabolized by the cytochrome P450 and mainly by CYP3A4, non-dihydropyridines are likely to inhibit their metabolism leading to a dangerous increase of their plasma concentration. Because VEGF is known to increase endothelial NO, antihypertensives that increase endogenous NO (e.g., nitrates, phosphodiesterase inhibitors, or the $\beta$-blocker nebivolol) might be of particular interest and merit evaluation in prospective clinical trials. ${ }^{69,70}$ Diuretics also have been used successfully to manage increases in BP arising from cancer treatment; however, thiazide-type diuretics should be used cautiously, particularly in patients prone to dehydration or hypercalcemia. ${ }^{71,72}$ Results from this literature review suggest that further clinical studies are needed to identify optimal treatments for managing targeted therapy-related HTN.

\section{Conclusions}

The relationship between VEGF inhibitors and HTN is to day well established, and clinicians must recognize that these drugs may aggravate cardiac risk factors. Early introduction or even prophylactic use of antihypertensive drugs can allow maintenance of therapy despite the onset of HTN. Specific recommendations about ASI use in patients with mRCC receiving targeted therapy cannot be made on the results of the data reported on the increase of survival. Finally, no clear recommendation for an antihypertensive agent can be made in this context and further clinical collaborative research is necessary to direct both VEGFi anticancer treatment and management of its side effects such as HTN to a more personalized strategy.

\section{References}

1. Häggström C, Rapp K, Stocks T, et al. Metabolic factors associated with risk of renal cell carcinoma. PLoS One 2013;8:e57475.

2. Chow W-H, Dong LM, Devesa SS. Epidemiology and risk factors for kidney cancer. Nat Rev Urol 2010;7:245-57.

3. Li Y, Li S, Zhu Y, et al. Incidence and risk of sorafenib-induced hypertension: a systematic review and meta-analysis. J Clin Hypertens 2014;16:177-85.

4. Qi W-X, He A-N, Shen Z, Yao Y. Incidence and risk of hypertension with a novel multi-targeted kinase inhibitor axitinib in cancer patients: a systematic review and meta-analysis. Br J Clin Pharmacol 2013;76:348-57.

5. Soria J-C, Massard C, Izzedine H. From theoretical synergy to clinical supra-additive toxicity. J Clin Oncol 2009;27:1359-61.

6. Escudier B, Eisen T, Stadler WM, et al. Sorafenib in advanced clearcell renal-cell carcinoma. N Engl J Med 2007;356:125-34.

7. Motzer RJ, Hutson TE, Tomczak P, et al. Sunitinib versus interferon alfa in metastatic renal-cell carcinoma. N Engl J Med 2007;356:115-24.

8. Motzer RJ, Escudier B, Tomczak P, et al. Axitinib versus sorafenib as second-line treatment for advanced renal cell carcinoma: overall survival analysis and updated results from a randomised phase 3 trial. Lancet Oncol 2013;14:552-62.

9. Qi W-X, Lin F, Sun Y-J, et al. Incidence and risk of hypertension with pazopanib in patients with cancer: a meta-analysis. Cancer Chemother Pharmacol 2013;71:431-9.

10. Rini BI, Melichar B, Ueda T, et al. Axitinib with or without dose titration for first-line metastatic renal-cell carcinoma: a randomised double-blind phase 2 trial. Lancet Oncol 2013;14:1233-42.

11. Izzedine H, Derosa L, Le Teuff G, et al. Hypertension and angiotensin system inhibitors: impact on outcome in sunitinibtreated patients for metastatic renal cell carcinoma. Ann Oncol Off J Eur Soc Med Oncol ESMO 2015;26:1128-33.

12. McKay RR, Rodriguez GE, Lin X, et al. Angiotensin system inhibitors and survival outcomes in patients with metastatic renal cell carcinoma. Clin Cancer Res Off J Am Assoc Cancer Res 2015;21:2471-9.

13. Pouessel D, Culine S. High frequency of intracerebral hemorrhage in metastatic renal carcinoma patients with brain metastases treated with tyrosine kinase inhibitors targeting the vascular endothelial growth factor receptor. Eur Urol 2008;53:376-81.

14. Sternberg CN, Hawkins RE, Wagstaff J, et al. A randomised, doubleblind phase III study of pazopanib in patients with advanced and/or 
metastatic renal cell carcinoma: final overall survival results and safety update. Eur J Cancer 2013;49:1287-96.

15. Motzer RJ, Hutson TE, Cella D, et al. Pazopanib versus sunitinib in metastatic renal-cell carcinoma. N Engl J Med 2013;369:722-31.

16. Escudier B, Porta C, Bono P, et al. Randomized, controlled, doubleblind, cross-over trial assessing treatment preference for pazopanib versus sunitinib in patients with metastatic renal cell carcinoma: PISCES Study. J Clin Oncol Off J Am Soc Clin Oncol 2014 10;32:1412-8.

17. Escudier B, Bellmunt J, Négrier S, et al. Phase III trial of bevacizumab plus interferon alfa-2a in patients with metastatic renal cell carcinoma (AVOREN): final analysis of overall survival. J Clin Oncol. 2010;28:2144-50.

18. Rini BI, Halabi S, Rosenberg JE, et al. Bevacizumab plus interferon alfa compared with interferon alfa monotherapy in patients with metastatic renal cell carcinoma: CALGB 90206. J Clin Oncol Off J Am Soc Clin Oncol 2008;26:5422-8.

19. Rini BI, Halabi S, Rosenberg JE, et al. Phase III trial of bevacizumab plus interferon alfa versus interferon alfa monotherapy in patients with metastatic renal cell carcinoma: final results of CALGB 90206. J Clin Oncol Off J Am Soc Clin Oncol 2010;28:2137-43.

20. Choueiri TK, Escudier B, Powles T, et al. Cabozantinib versus everolimus in advanced renal-cell carcinoma. $\mathrm{N}$ Engl $\mathrm{J}$ Med 2015;373:1814-23.

21. Midgley R, Kerr D. Bevacizumab — current status and future directions. Ann Oncol Off J Eur Soc Med Oncol ESMO 2005;16:999-1004.

22. An MM, Zou Z, Shen H, et al. Incidence and risk of significantly raised blood pressure in cancer patients treated with bevacizumab: an updated meta-analysis. Eur J Clin Pharmacol 2010;66:813-21.

23. Zhu X, Wu S, Dahut WL, Parikh CR. Risks of proteinuria and hypertension with bevacizumab, an antibody against vascular endothelial growth factor: systematic review and meta-analysis. Am J Kidney Dis Off J Natl Kidney Found 2007;49:186-93.

24. Wilhelm SM, Carter C, Tang L, et al. BAY 43-9006 exhibits broad spectrum oral antitumor activity and targets the RAF/MEK/ERK pathway and receptor tyrosine kinases involved in tumor progression and angiogenesis. Cancer Res 2004;64:7099-109.

25. Wu S, Chen JJ, Kudelka A, et al. Incidence and risk of hypertension with sorafenib in patients with cancer: a systematic review and meta-analysis. Lancet Oncol 2008;9:117-23.

26. Chow LQM, Eckhardt SG. Sunitinib: from rational design to clinical efficacy. J Clin Oncol Off J Am Soc Clin Oncol 2007;25:884-96.

27. Zhu X, Stergiopoulos K, Wu S. Risk of hypertension and renal dysfunction with an angiogenesis inhibitor sunitinib: systematic review and meta-analysis. Acta Oncol Stockh Swed 2009;48:9-17.

28. Bukowski RM, Yasothan U, Kirkpatrick P. Pazopanib. Nat Rev Drug Discov 2010;9:17-8.

29. Bukowski RM. Pazopanib: a multikinase inhibitor with activity in advanced renal cell carcinoma. Exp Rev Anticancer Ther 2010;10:635-45.

30. Hu-Lowe DD, Zou HY, Grazzini ML, et al. Nonclinical antiangiogenesis and antitumor activities of axitinib (AG-013736), an oral, potent, and selective inhibitor of vascular endothelial growth factor receptor tyrosine kinases 1, 2, 3. Clin Cancer Res Off J Am Assoc Cancer Res 2008;14:7272-83.

31. Rini BI, Quinn DI, Baum M, et al. Hypertension among patients with renal cell carcinoma receiving axitinib or sorafenib: analysis from the randomized phase III AXIS trial. Target Oncol 2015;10:45-53.

32. Elisei R, Schlumberger MJ, Müller SP, et al. Cabozantinib in progressive medullary thyroid cancer. J Clin Oncol 2013;31:3639-46.

33. Kappers MHW, Esch JHM van, Sluiter W, et al. Hypertension induced by the tyrosine kinase inhibitor sunitinib is associated with increased circulating endothelin-1 levels. Hypertension 2010;56:675-81.
34. Horowitz JR, Rivard A, Zee R van der, et al. Vascular endothelial growth factor/vascular permeability factor produces nitric oxidedependent hypotension evidence for a maintenance role in quiescent adult endothelium. Arterioscler Thromb Vasc Biol 1997;17:2793-800.

35. Hood JD, Meininger CJ, Ziche M, Granger HJ. VEGF upregulates ecNOS message, protein, and NO production in human endothelial cells. Am J Physiol 1998;274:H1054-8.

36. Sane DC, Anton L, Brosnihan KB. Angiogenic growth factors and hypertension. Angiogenesis 2004;7:193-201.

37. Gordon MS, Cunningham D. Managing patients treated with bevacizumab combination therapy. Oncology 2005;69 Suppl 3:25-33.

38. Mourad J-J, des Guetz G, Debbabi H, Levy BI. Blood pressure rise following angiogenesis inhibition by bevacizumab. A crucial role for microcirculation. Ann Oncol Off J Eur Soc Med Oncol ESMO 2008;19:927-34.

39. Eremina V, Jefferson JA, Kowalewska J, et al. VEGF inhibition and renal thrombotic microangiopathy. N Engl J Med 2008;358:1129-36.

40. Daemen MJ, Lombardi DM, Bosman FT, Schwartz SM. Angiotensin II induces smooth muscle cell proliferation in the normal and injured rat arterial wall. Circ Res 1991;68:450-6.

41. Tamarat R, Silvestre J-S, Durie M, Levy BI. Angiotensin II angiogenic effect in vivo involves vascular endothelial growth factor- and inflammation-related pathways. Lab Investig J Tech Methods Pathol 2002;82:747-56.

42. Fernandez LA, Twickler J, Mead A. Neovascularization produced by angiotensin II. J Lab Clin Med 1985;105:141-5.

43. Chiu T, Santiskulvong C, Rozengurt E. ANG II stimulates PKCdependent ERK activation, DNA synthesis, and cell division in intestinal epithelial cells. Am J Physiol Gastrointest Liver Physiol 2003;285:G1-11.

44. Folkman J, Watson K, Ingber D, Hanahan D. Induction of angiogenesis during the transition from hyperplasia to neoplasia. Nature 1989;339:58-61.

45. Kosaka T, Miyajima A, Takayama E, et al. Angiotensin II type 1 receptor antagonist as an angiogenic inhibitor in prostate cancer. Prostate 2007;67:41-9.

46. Escobar E, Rodríguez-Reyna TS, Arrieta 0, Sotelo J. Angiotensin II, cell proliferation and angiogenesis regulator: biologic and therapeutic implications in cancer. Curr Vasc Pharmacol 2004;2:385-99.

47. Uemura H, Nakaigawa N, Ishiguro H, Kubota Y. Antiproliferative efficacy of angiotensin II receptor blockers in prostate cancer. Curr Cancer Drug Targets 2005;5:307-23.

48. Hii SI, Nicol DL, Gotley DC, et al. Captopril inhibits tumour growth in a xenograft model of human renal cell carcinoma. Br J Cancer 1998;77:880-3.

49. Ishiguro H, Ishiguro Y, Kubota Y, Uemura H. Regulation of prostate cancer cell growth and PSA expression by angiotensin II receptor blocker with peroxisome proliferator-activated receptor gamma ligand like action. Prostate 2007;67:924-32.

50. Funao K, Matsuyama M, Kawahito Y, et al. Telmisartan is a potent target for prevention and treatment in human prostate cancer. Oncol Rep 2008;20:295-300.

51. Dolley-Hitze T, Jouan F, Martin B, et al. Angiotensin-2 receptors (AT1-R and AT2-R), new prognostic factors for renal clear-cell carcinoma? Br J Cancer 2010;103:1698-705.

52. Song T, Choi CH, Kim MK, et al. The effect of angiotensin system inhibitors (angiotensin-converting enzyme inhibitors or angiotensin receptor blockers) on cancer recurrence and survival: a meta-analysis. Eur J Cancer Prev Off J Eur Cancer Prev Organ ECP 2016 [Epub ahead of print].

53. Verhoest G, Dolley-Hitze T, Jouan F, et al. Sunitinib combined with angiotensin-2 type-1 receptor antagonists induces more necrosis: a murine xenograft model of renal cell carcinoma. Bio Med Res Int 
2014;2014:901371.

54. Keizman D, Huang P, Eisenberger MA, et al. Angiotensin system inhibitors and outcome of sunitinib treatment in patients with metastatic renal cell carcinoma: a retrospective examination. Eur J Cancer 2011;47:1955-61.

55. Huillard 0, Xylinas E, Peyromaure M, et al. Angiotensin system inhibitors in renal cell carcinoma-letter. Clin Cancer Res 2016;22:524.

56. Hamnvik 0-PR, Choueiri TK, Turchin A, et al. Clinical risk factors for the development of hypertension in patients treated with inhibitors of the VEGF signaling pathway. Cancer 2015;121:311-9.

57. Sorich MJ, Kichenadasse G, Rowland A, et al. Angiotensin system inhibitors and survival in patients with metastatic renal cell carcinoma treated with VEGF-targeted therapy: a pooled secondary analysis of clinical trials. Int J Cancer 2016;138:2293-9.

58. National High Blood Pressure Education Program. The Seventh Report of the Joint National Committee on Prevention, Detection, Evaluation, and Treatment of High Blood Pressure. Bethesda (MD): National Heart, Lung, and Blood Institute (US); 2004. Available from: http://www.ncbi.nlm.nih.gov/books/NBK9630/ Accessed: 29 May 2016.

59. Mancia G, Fagard R, Narkiewicz K, et al. 2013 ESH/ESC Guidelines for the management of arterial hypertension: the Task Force for the management of arterial hypertension of the European Society of Hypertension (ESH) and of the European Society of Cardiology (ESC). J Hypertens 2013;31:1281-357.

60. Azizi M, Chedid A, Oudard S. Home blood-pressure monitoring in patients receiving sunitinib. N Engl J Med 2008;358:95-7.

61. Bamias A, Lainakis G, Manios E, et al. Could rigorous diagnosis and management of hypertension reduce cardiac events in patients with renal cell carcinoma treated with tyrosine kinase inhibitors? J Clin Oncol Off J Am Soc Clin Oncol 2009;27:2567-70.

62. Bamias A, Lainakis G, Manios E, et al. Diagnosis and management of hypertension in advanced renal cell carcinoma: prospective evaluation of an algorithm in patients treated with sunitinib. J Chemother 2009;21:347-50.

63. Maitland ML, Bakris GL, Black HR, et al. Initial assessment, surveillance, and management of blood pressure in patients receiving vascular endothelial growth factor signaling pathway inhibitors. JNCI J Natl Cancer Inst 2010;102:596-604.

64. Izzedine H, Ederhy S, Goldwasser F, et al. Management of hypertension in angiogenesis inhibitor-treated patients. Ann Oncol 2009;20:807-15.

65. Lewis EJ, Hunsicker LG, Clarke WR, et al. Renoprotective effect of the angiotensin-receptor antagonist irbesartan in patients with nephropathy due to type 2 diabetes. N Engl J Med 2001;345:851-60.

66. Brenner BM, Cooper ME, de Zeeuw D, et al. Effects of losartan on renal and cardiovascular outcomes in patients with type 2 diabetes and nephropathy. N Engl J Med 2001;345:861-9.

67. Bhojani N, Jeldres C, Patard J-J, et al. Toxicities associated with the administration of sorafenib, sunitinib, and temsirolimus and their management in patients with metastatic renal cell carcinoma. Eur Urol 2008;53:917-30.

68. Hutson TE, Figlin RA, Kuhn JG, Motzer RJ. Targeted therapies for metastatic renal cell carcinoma: an overview of toxicity and dosing strategies. Oncologist 2008;13:1084-96.

69. Dirix LY, Maes H, Sweldens C. Treatment of arterial hypertension (AHT) associated with angiogenesis inhibitors. Ann Oncol Off J Eur Soc Med Oncol ESMO 2007;18:1121-2.

70. Oliver JJ, Melville VP, Webb DJ. Effect of regular phosphodiesterase type 5 inhibition in hypertension. Hypertension 2006;48:622-7.

71. Jain M, Townsend RR. Chemotherapy agents and hypertension: a focus on angiogenesis blockade. Curr Hypertens Rep 2007;9:320-8.

72. Porta C, Szczylik C. Tolerability of first-line therapy for metastatic renal cell carcinoma. Cancer Treat Rev 2009;35:297-307. 